\title{
Prometeu Acorrentado: Análise Sociológica da Categoria Produtividade e as Condições Atuais da Vida Acadêmica
}

\author{
MADEL T. LUZ \\ Insulta agora daqui os deuses, ó Prometeu! Rouba-lhes as \\ honras divinas, para dá-las a seres que não viverão mais \\ que um dia! Poderão por acaso os mortais minorar teu \\ suplício? Em vão te deram os deuses o nome de Prometeu \\ (“o previdente, o que prevê”)! Tu sim! - precisas de um \\ Prometeu que te liberte! \\ (Prometeu Acorrentado. Tragédia de Ésquilo).
}

\section{RESUMO}

$\mathrm{O}$ artigo propõe-se a analisar certas relações, presentes na sociedade contemporânea, entre regime de produção intelectual, pesquisa e a categoria "produtividade", vista como manifestação privilegiada do conhecimento científico. Tal categoria é importada de estrutura econômica e aplicada ao trabalho intelectual. Procura-se evidenciar como a lógica da produtividade das máquinas ou de setores específicos da produção de conhecimento, sem provocar dano à saúde dos pesquisadores, e mesmo à própria produtividade científica, desconsidera objetivos, ritmos, formas de produzir e divulgar o trabalho científico, em suas múltiplas versões disciplinares.

Palavras-chave: Ciência; pesquisa; produtividade; trabalho; sofrimento.

Recebido em: 10/06/2005.

Aprovado em: 27/06/2005. 


\section{Nota Introdutória: por que "Prometeu acorrentado"?}

Uma pequena nota introdutória antes de iniciar: por que atribuir o título "Prometeu acorrentado" ao trabalho? Lembremo-nos que esse titã da mitologia grega foi punido por ter roubado aos deuses o fogo sagrado do conhecimento e tê-lo entregue aos homens. Amarrado firmemente por correntes de ferro a um rochedo inacessível junto ao mar, tinha durante o dia seu fígado devorado por um abutre enviado por Júpiter (Zeus) para atormentá-lo indefinidamente (uma vez que o fígado se refazia durante a noite), lembrando-o ao mesmo tempo de sua impotência face ao poder invencível dos deuses, e de sua arrogância em ter possibilitado a seres inferiores e frívolos (a humanidade) o poder de criar e inventar indefinidamente sua vida, prerrogativa considerada divina.

Interpretações clássicas da mitologia assimilam o "fogo sagrado" roubado à ciência, ou mais geralmente ao conhecimento, e sua capacidade de transformar continuamente a natureza e a vida humana. Neste artigo é feita uma identificação metafórica entre Prometeu e os cientistas ou, mais modestamente, nós, modestos pesquisadores docentes das atuais estruturas universitárias. Uma analogia é feita entre as condições atuais da produção acadêmica, ou trabalho científico, e a situação trágica do audacioso titã. Quanto a Zeus, ou seu cruel abutre, deixo aos leitores a tarefa de identificar quem atualmente cumpre as funções de quem. Apenas um lembrete que vale a pena ter como "dica" (ou diké, se quisermos ser mitológicos até o fim): a avaliação de tal produção é em sua maior parte realizada atualmente por "pares", isto é, por nós mesmos pesquisadores. Voltaremos a essa questão no final destas páginas...

O trabalho que desenvolveremos nas páginas seguintes é, portanto, como seu título o indica, uma tentativa de análise sociológica sobre as condições em que se desenvolve, na sociedade capitalista globalizada, tendo como referência o Brasil, o trabalho intelectual universitário. Mais especificamente, sobre o que é rotulado institucionalmente como produção científica. A intenção é estabelecer um debate, ou ao menos trazer à baila para a discussão na comunidade científica, sobretudo a da área da Saúde Coletiva, um conjunto de reflexões resultantes de experiências de ensino, pesquisa e de participação em comitês de avaliação de agências de fomento à pesquisa nas últimas três décadas, além de observação empírica, ainda que não sistematizada em forma de projeto, sobre as mudanças que vêm ocorrendo nas condições do trabalho universitário. $\mathrm{O}$ artigo dá seqüência ao capítulo "Fragilidade social e busca de cuidado na 
sociedade civil contemporânea" da coletânea intitulada Cuidado: as fronteiras da Integralidade (PINHEIRO e MATTOS, 2004), mas tem suas raízes em outro capítulo: "O futuro do ensino das ciências sociais- por uma ética pedagógica" de 1991, da coletânea intitulada As assim chamadas ciências sociais (BOHMENI e BIRMAN, 1991).

Nesses capítulos tomamos como tema de análise algumas condições sociais de trabalho, sobretudo o acadêmico, e suas repercussões sobre o ato de produzir. No capítulo de 2004 consideramos importante para análise a contínua geração de estresse, sofrimento e adoecimento dos atores, a partir da aceleração do ritmo de atividades, da instabilidade no emprego e do aumento de exigências de "produtividade", sem correspondente valorização estatutária ou econômica, que afetam na sociedade contemporânea a situação de milhares de profissionais com formação do ensino superior, sobretudo na Universidade e na área de Saúde, vistas como situs institucional de inserção no mundo do trabalho.

Embora adote um tom pessimista, o trabalho tem a esperança (afinal, junto com o fogo do conhecimento, Prometeu lega aos homens a divina esperança) de que as reflexões expostas possam nos ajudar a ver com mais clareza as atuais condições de trabalho, principalmente o universitário, no sentido de buscar alternativas ao modo pelo qual a produção acadêmica vem-se processando nos últimos quinze anos. Ajudar-nos, sobretudo, a buscar mudar o ritmo e os valores com que se vêm processando, considerados os danos que tais valores e ritmo vêm acarretando para a saúde física e mental de professores e pesquisadores. Deve ser acentuado, inclusive, que tais danos repercutem também sobre a saúde de alunos e orientandos de teses, dissertações e monografias, pois o estresse continuado de mestres e orientadores acaba "desabando" parcialmente sobre os alunos, como os dos médicos, enfermeiros e auxiliares sobre os pacientes.

Em última instância, consideramos como elevados os prejuízos que essa situação tende a acarretar para as próprias atividades de ensino e pesquisa de todos os atores envolvidos, inclusive os ligados ao apoio técnico e administrativo.

\section{Pesquisa, Ciência, Produção de Conhecimento, Produtividade: emblemas da criação discursiva legitimada da modernidade}

Há mais de dois séculos legitimadas nas Academias como as finalidades básicas da vida universitária, as atividades de pesquisa são definidas pela 
invenção, fruto de criatividade individual ou coletiva ("inovação" em jargão institucional), pela produção de proposições verificáveis por experiência controlada (ciência), e pela capacidade de intervir e transformar a ordem da vida, ou natureza (tecnologia) que possam ter essas proposições.

Nosso propósito principal aqui é demonstrar, ainda que sobre base hipotética, provisória, que o modo de produção de conhecimento estabelecido há três séculos com a racionalidade moderna, ainda vigente (LUZ, 2004b), tende, no que concerne tanto à organização institucional do produzir, como às relações sociais implicadas nesse produzir, e o ritmo com que se processa tal produção, cuja aferição quantitativa é conhecida em jargão institucional como produtividade, a ensejar danos à saúde daqueles que estão submetidos a tal regime ou ordem social de produção. Mais ainda, tende, no longo prazo, a ferir o próprio coração (hard core) ou a fonte seminal de todo esse sistema de produção de conhecimento, que é a criatividade, origem da inovação. A produção contínua de proposições inovadoras, que se renovam sem cessar, expressão do progresso científico, moto perpétuo da ciência moderna, só é possível quando há uma certa liberdade no produzir que possibilita o surgimento do novo, com a criação, que está na origem da inovação científica, tanto quanto na arte. E essa liberdade supõe um ritmo próprio de operação, de elaboração, de avanços e pausas durante o desenvolvimento das atividades precípuas de investigação, variável de acordo com os distintos ramos da "árvore do conhecimento", mas muito distinto do das máquinas, ao qual vem sendo assimilada a categoria produtividade (LUZ, 2004a). Os pesquisadores, apesar de todo o esforço que empregam para serem "produtivos", não são máquinas. Sobretudo, não são máquinas em competição para reduzir custos na confecção de produtos renováveis a intervalos de tempo cada vez menores. O desconhecimento desse fato pode gerar (e tem gerado) conseqüências desastrosas para a saúde de toda essa categoria profissional. Ciosos da necessidade de atender às exigências institucionais vigentes, obsessivos quanto ao cumprimento das normas da "produtividade", crescentes, aliás, em termos de qualidade e quantidade, os bravos guerreiros da ciência se esforçam para desincumbir-se de suas tarefas à exaustão, sacrificando repouso, lazer e férias em favor do trabalho (LUZ, 2004a).

Queremos esclarecer, entretanto, que não se trata aqui de escrever um ensaio visando a tecer loas ao avanço da produtividade dos pesquisadores brasileiros - bastante expressiva, em números absolutos e relativos, durante a década de 90, de acordo com levantamentos e estudos produzidos pelas principais 
agências de fomento (CNPq e CAPES) - ou de clamar pela injustiça da deterioração salarial e do emprego (tão reais quanto o aumento de sua produtividade) de que são vítimas há mais de uma década. E isto, em primeiro lugar, porque pensamos que é função precípua do pesquisador pesquisar, por mais tautológica que pareça tal afirmação. Em seguida, porque pensamos também que cabe aos sindicatos e associações profissionais a que nos afiliamos, e nos quais militamos, o papel das denúncias e reivindicações no que concerne às más condições de trabalho e à baixa remuneração de seus afiliados. Papel que bem ou mal (às vezes mais mal do que bem, consideradas algumas estratégias que terminam sistematicamente em fracasso) vêm cumprindo.

Aqui faremos "denúncias", sim, mas de outros aspectos relativos à produção acadêmica. É necessário enunciá-las desde logo, para que não restem dúvidas quanto aos objetivos destas reflexões: queremos nos referir principalmente à questão dos efeitos desagregadores sobre a atividade científica gerados pelos aspectos sociais das políticas de educação e ciência e tecnologia dominantes a partir do início dos anos 90, isto é, desde o governo de Fernando Henrique Cardoso. Tais políticas são em grande parte centradas na categoria de produtividade (do agente pesquisador, ou do programa institucional de pesquisa em que este se insere).

A categoria é geralmente entendida como quantum de produção intelectual, sobretudo bibliográfica, desenvolvida num espaço de tempo específico, crescente de acordo com a qualificação acadêmica ("titulação") do professor/pesquisador. Esse quantum básico é necessário para conservar os pesquisadores na sua posição estatutária em seu campo científico. A categoria analítica campo, aqui empregada, é assimilada das análises sobre trabalhadores da ciência e sua produção, feitas pelo sociólogo Pierre Bourdieu $(1989,1998)$. O quantum de produção é estipulado atualmente, em quase todos os campos disciplinares, em termos de papers editados em periódicos de circulação nacional ou internacional, cuja qualidade de divulgação (base Qualis) é estabelecida por cada área de conhecimento.

A categoria produtividade, interiorizada das atividades econômicas para o trabalho intelectual (LUZ, 2004a), pode atuar positiva ou negativamente sobre as características de inovação, originalidade e cumulatividade (entendida aqui em termos de produção sustentada), marcas seculares do trabalho acadêmico, de acordo com as normas que estabeleça e com o grau de formalidade que se aplique à produção dos agentes. De nosso ponto de vista, 
tal categoria tem atuado mais negativa que positivamente sobre os produtores, quando levados em consideração os agentes que produzem e a sobrecarga de trabalho exercida sobre eles, e não os beneficiários diretos e indiretos de sua produção: isto é, o Estado, as empresas, a ordem política e social. Em última instância, a própria sociedade civil.

Investidas pelo Estado, através das agências de fomento, as atividades de pesquisa se concentram atualmente nos programas de pós-graduação das instituições públicas universitárias, sendo os principais atores do processo os docentes, transformados de mestres do ensino em agentes produtores da ciência. Através dos editais, o poder público vem determinando em grande parte a oferta de subsídios a uma atividade tornada cara pela sofisticação tecnológica implicada. Conduz (ou induz, para empregar o termo institucional), de acordo com os variáveis interesses da política governamental, não apenas os eixos temáticos de investigação ( $o$ que pesquisar), como também o roteiro metodológico a ser seguido pelos pesquisadores (como pesquisar), e a lista de "produtos" que devem resultar do processo da pesquisa (os resultados). O pesquisador é avaliado pela quantidade de produtos que é capaz de extrair de seus projetos. Quanto mais produtos, maior sua "produtividade".

Inútil acentuar que os estudiosos que podem ter outros temas a investigar, independentemente de seu potencial inovador, são praticamente excluídos da possibilidade de pesquisar, concorrendo com milhares de outros pesquisadores por uns poucos subsídios, à chamada demanda de balcão. Chamamos a atenção aqui para o intenso estresse gerado por essa situação, e suas consequiências sobre a saúde dos agentes pesquisadores. A burocratização progressiva da ciência, efeito colateral do processo denominado indutivo, vemse tornando uma cadeia de ferro para a produção verdadeiramente criativa e inovadora. Os deuses do Olimpo estatal mantêm o mesmo controle do abutre mítico sobre o novo Prometeu coletivo da ciência, mordendo-lhe continuamente o fígado, através da exigência dos constantes relatórios parciais e finais, das avaliações periódicas em espaços de tempo cada vez mais curtos, dos inquéritos sobre pendências contábeis referidos às vezes a uns poucos trocados imprudentemente gastos em algum lanche coletivo, ou em passagens nacionais necessárias ao desenvolvimento do projeto, ou à visita não prevista de outro pesquisador, ou casos semelhantes. A vigilância é permanente: nenhum delito aos cofres públicos deve ser cometido por esses agentes, política e simbolicamente tidos como heróis do conhecimento, mas burocraticamente tratados como empregados públicos que têm contas a prestar de cada centavo 
que recebem, como se o que fizessem não fosse para benefício da coletividade. Os mecenas do início da modernidade foram mais generosos para com seus filósofos e cientistas que o Estado contemporâneo. Os pesquisadores atuais acabam tornando-se gladiadores hodiernos, considerada a disputa "até a morte" travada entre eles pelos subsídios anunciados nos editais, sempre insuficientes face à crescente demanda.

Situamos na década de 70 o marco inicial dessa concepção e política da pós-graduação como nicho institucional legitimado e privilegiado da pesquisa no país, gerando com isto um trágico equívoco pedagógico para a nação. Esta concepção está na raiz da escolha da concentração da atividade de pesquisa no cume do sistema educacional e da hierarquização dos "produtores".

As políticas públicas de ciência e tecnologia começaram a se estruturar como tal na década de 50 do século XX, fundamentalmente através das grandes agências de fomento à pesquisa, ainda hoje as mesmas (CNPq e CAPES). Atualmente estão ligadas tanto ao Ministério da Educação, quanto ao da Ciência e Tecnologia, ou ainda a Agências Regionais de Ciência e Tecnologia, como as Fundações Estaduais de Amparo à Pesquisa (FAP). Entretanto, foram desde seu início, e continuam a ser implementadas, principalmente nas universidades públicas, sobretudo através das pró-reitorias de ensino e pesquisa, transmitindose assim verticalmente como "correias de transmissão" do poder central do Estado para as instituições acadêmicas.

Deste ponto de vista, queremos analisar também, nestas páginas, certas relações sociais recentes entre políticas de Estado e instituições, e seus efeitos sobre sujeitos individuais ou atores institucionais no campo da produção do conhecimento científico e tecnológico. Nesta análise não nos situamos do ponto de vista do planejador, do gestor, ou do avaliador de políticas. Nosso lugar de discurso é o de sujeito pesquisador e, principalmente, o do sociólogo que analisa criticamente relações sociais entre atores, instituições e políticas, sobretudo em relação à produção em ciência, coerentemente com nossa tradição de pesquisa nessa área temática (LUZ, 1979, 1982, 1991, 2000, 2003, 2004a e 2004b).

Nesta perspectiva, não pretendemos isolar, na análise, os efeitos das políticas científicas na produção acadêmica dos agentes, da mudança de valores em curso na sociedade capitalista, globalizada já nos anos 80, nem do avanço do individualismo e da competição compulsiva que tal mudança gerou entre os sujeitos individuais e coletivos em todos os setores da vida, principalmente no 
trabalho. Menos ainda das mudanças na organização e nas relações de trabalho impostas pelo regime de produção internacionalizado que estão na origem da transformação, ou mesmo da perda de certos valores culturais e éticos (LUZ, 2003 e 2004b). Cremos, inclusive, que só uma análise sintetizada desses três aspectos estruturais: o das políticas sociais financeiramente restritivas e seus efeitos sobre a atividade científica, o dos valores individualistas hegemônicos na cultura contemporânea, e o da reestruturação do trabalho resultante da economia globalizada, com a precarização do emprego e das relações no emprego, revertendo direitos e situações legais há décadas asseguradas (LUZ, 1997 e 2004b) poderá ajudar-nos a entender e a interpretar a situação de quase inviabilidade em que se encontra a produção acadêmica potencial e autenticamente produtiva.

Desejamos qualificar com esse termo uma produção livre, inovadora, cumulativa e comprometida com a situação social e tecnológica do país e, ao mesmo tempo, com real possibilidade de socialização de seus resultados, através de difusão ampla e democrática, sem as "cartas marcadas" dos veículos Qualis, que não passam, em sua quase totalidade, de bases catalográficas de periódicos, geralmente privadas, que nada dizem ou permitem ver da qualidade dos produtos nelas veiculados ${ }^{1}$. Estes afirmam simplesmente a "excelência" (estipulada pelo índice de citações/impacto dos produtos num campo específico disciplinar) do veículo em que a produção é difundida para sua comunidade de pares. Tais bases se tornaram, em determinadas áreas disciplinares, o dogma sobre o qual repousa a classificação hierarquizada da produção dos pesquisadores e de seus programas.

Sem consideração do real mérito ou relevância de seus "produtos", a classificação resultante do dogma acaba tendo profundas repercussões políticas e conseqüências de natureza psicossocial sobre os atores e seus nichos acadêmicos de inserção, pois dela resultam freqüentemente desqualificações de pesquisadores e de programas de pós-graduação. Inútil reafirmar aqui o grau de estresse no trabalho e o sofrimento psíquico implicados nesse processo, tanto para docentes pesquisadores como para dirigentes de programas. Mas é muito importante sublinhar o movimento de competição desenfreada para "subida de conceito" que o processo desencadeia em nível individual e institucional, com evidente conseqüência para a saúde de todos os implicados, visível em somatizações de todos os tipos, face ao agravamento do ambiente de isolamento e hostilidade no trabalho provocado pelos valores individualistas (LUZ, 2004b). 
Ambiente que não facilita em nada o intercâmbio, o compartilhamento de informações e a socialização de métodos e resultados que em princípio caracterizariam as regras do jogo da produção científica.

\section{As Instituições de Pesquisa e as Políticas Recentes de Ciência e Tecnologia: suas repercussões no trabalho acadêmico}

Como afirmamos acima, a política de ciência e tecnologia da década de 70, sob regime autoritário, dá início à concepção e à prática da pós-graduação como nicho institucional da pesquisa no país, gerando com isto, de nosso ponto de vista, um erro histórico trágico para o projeto educacional brasileiro. Por um lado criou-se o equivocado binômio institucional ensino/pesquisa, na verdade um gap entre as duas atividades jamais superado, nem mesmo na pós-graduação. Por outro, hierarquizou-se em forma de pirâmide o sistema universitário (graduação/ pós-graduação), concentrando no seu alto uma prática que deveria, ao contrário, generalizar-se para lograr atingir um patamar largo e extenso de desenvolvimento da atividade científica (um grande "platô" científico), se o desejo era mesmo, conforme apregoava o discurso oficial, que a nação atingisse um nível internacional - "excelente" - de inserção tecnológica com vistas ao crescimento econômico, e conseqüente superação do subdesenvolvimento.

Não é função deste artigo discutir tal concepção, ela própria uma concepção mecânica e, a nosso ver, equivocada de desenvolvimento econômico (sinônimo de crescimento associado ao desenvolvimento e aquisição de tecnologias avançadas), que acompanha a história das últimas seis décadas da República. Grandes mestres da economia política brasileira, como Celso Furtado, e estudiosos "brazilianistas" ", já o vêm fazendo sem serem ouvidos há praticamente meio século (FURTADO, 1974 e 1984; SKIDMORE, 1975). Basta salientar que essa concepção inalterada está na raiz da escolha da concentração da atividade de pesquisa no cume do sistema educacional público ${ }^{3}$.

Mas como toda hierarquização institucional acaba tendo um efeito social, pois é ela mesma um processo social, a escolha mencionada resultou no isolamento da atividade científica no alto da pirâmide educacional, isto é, nos programas de pós-graduação senso estrito que começaram a pipocar em todas as áreas do conhecimento a partir dos anos 80, gerando uma elitização irreversível da prática da pesquisa, e a desvalorização do ensino historicamente inéditas, inclusive pela estreita base dessa produção até a década de 60 . 
É verdade que, por sua reduzida proporção na atividade educacional como um todo, a prática sistemática da pesquisa concentrava-se, até os anos 60, em alguns institutos e em certas disciplinas científicas "duras", como Física, Matemática e Astronomia, e as disciplinas biomédicas sediadas no Instituto Oswaldo Cruz, com seus similares em outros estados do país. O ensino universitário seguia em grande parte um padrão canônico clássico, de transmissão informativa do conhecimento acumulado nas disciplinas, nem sempre atualizada, e de reprodução dos saberes consagrados pelo "paradigma normal" da ciência, no melhor dos casos. A atividade da pesquisa, minoritária nesse modelo canônico, centrava-se em figuras carismáticas, os catedráticos, e seus associados e seguidores, dispostos em rigorosa hierarquia.

No entanto, essa atividade se realizava durante o curso de graduação. Muitos "monitores", que corresponderiam atualmente em grande parte aos bolsistas de iniciação científica, dedicavam-se não apenas a repassar, ou mesmo a dar as aulas de um catedrático ou de seu assistente, mas também a participar da equipe do mestre. Neste sentido, as monitorias foram um importante elemento institucional formador do futuro professor/pesquisador, futuro mestre, nos anos 50, 60 e ainda 70 do século recém-findo.

Para exemplificar: no momento da reforma universitária, durante o período militar, com a criação do ciclo básico de disciplinas, incluindo posterior "especialização disciplinar" por carreiras, não se podia deduzir a priori que a pesquisa na graduação fosse dispensável - ao contrário. Os departamentos tinham seus projetos de pesquisa centrados nos professores titulares ou adjuntos, incorporando monitores, auxiliares de pesquisa, assistentes etc. A atividade era minoritária no sistema, mas existia, variando em intensidade e volume de acordo com as instituições e suas tradições, e os distintos campos disciplinares.

O primeiro projeto de pesquisa significativo, que pudemos coordenar na Universidade Federal da Paraíba, em 1970, por exemplo, se desenvolvia no nível da graduação do Departamento de Ciências Sociais e incorporava vários alunos como bolsistas ou "auxiliares de campo". Estes exerciam o mesmo papel e desenvolviam as mesmas tarefas que os atuais bolsistas de iniciação, aperfeiçoamento, apoio técnico etc. atrelados à nossa pós-graduação.

A ruptura com a prática de pesquisa na graduação, gerada ainda no regime autoritário, e a decisão de concentrar a investigação científica nos programas de pós-graduação ou em institutos superiores de pesquisa, significou 
um duro golpe para aquele nível de estudos, prejudicando profundamente seu desenvolvimento posterior, ao menos em termos qualitativos.

A desvalorização desse nível educacional - a graduação - e o conseqüente esvaziamento da procura de professores interessados em formarse para o ensino no terceiro grau, acentuaram-se a partir dos anos 80 , atingindo o auge nos 90. Formou-se um "cone" social competitivo em torno do curso de doutorado, esvaziando progressivamente, por sua vez, o próprio nível inicial da pós-graduação voltado para o ensino/pesquisa, destinado a formar mestres: o nível do mestrado acadêmico. O deslocamento da concentração das atividades de pesquisa para o nível do doutorado foi mera questão de tempo e decorreu no breve espaço de uma década, a década de 90.

Ironicamente essa elitização produziu, na atualidade, seu contrário, que é a própria desvalorização econômica do título de doutor. Por um lado, a pletora de titulados em relação ao sistema universitário público, considerando-se o fechamento institucional do mesmo para amplos concursos há mais de uma década (contratações em "conta-gotas", geralmente para preenchimento substitutivo de vagas por mortes e aposentadorias) não absorve os novos doutores no ensino da já saturada pós-graduação. Por outro lado, há uma incapacidade manifesta de o sistema de ensino privado, mercantilizado e sem espaço institucional para a pesquisa (exceção das grandes universidades confessionais e de algumas poucas universidades privadas portadoras de projeto pedagógico) absorver a mão-de-obra qualificada, pelo acréscimo de custo/hora que representam os doutores, mesmo que seja de uns poucos reais. De acordo com Renato Mezan, conhecido professor titular da PUC de São Paulo, em sua brilhante análise sobre a "doutorização" do ensino superior:

\footnotetext{
“A ‘discriminação contra doutores', por motivos que beiram o ridículo -mais R\$ 10 por hora aula - na maioria das vezes é um dos escândalos mais grotescos que encontramos nesse amontoado de aberrações em que se converteu o ensino superior neste país" (MEZAN, 2005, p. 3).
}

Pode-se constatar o crescimento constante de doutores desempregados no sistema, por serem overqualified para as funções disponíveis no mercado de trabalho brasileiro, já que nossas grandes empresas não têm tradição de investimento em pesquisa, diferentemente das nações centrais do capitalismo, sobretudo Estados Unidos. A tecnologia produzida no país em alguns setores estratégicos da economia atual, com a finalidade de ser internacionalmente 
competitiva, quando o é, é graças ao saber e à prática da pesquisa acadêmica. Mesmo as exceções, neste caso, ainda mantêm, de uma forma ou de outra, ligação umbilical com os institutos de pesquisa universitários.

Um comentário cauteloso quanto às normas vigentes, para não suscitar a impressão, nesta era do conhecimento e da informação, de saudosismo do ancien régime do ensino superior ${ }^{4}$, deve ser feito em relação à formação dos doutores dos últimos 15 anos. Diferentemente do processo pedagógico vigente nos anos 70-80, quando formar um doutor, ao menos na área de Ciências Sociais, podia levar quase uma década, e um mestre, de quatro a seis $a_{n o s}{ }^{5}$, na "formatação compactada" atual (quatro e dois anos, respectivamente) - mais uma vez indissociável, a nosso ver, da categoria institucional de produtividade não se forma um doutor, mas um especialista em uma linha de pesquisa, normalmente a do orientador.

Em geral esse "especialista" não sabe, nem tem vontade de ensinar", isto é, dar aulas e orientar, estando interessado apenas em sua carreira de pesquisador. Esta se resume, se depender de suas aspirações, à publicação de artigos nas revistas Qualis A de sua área, à eventual orientação de outros "especialistas", à apresentação de trabalhos em eventos científicos nacionais e internacionais, bem como a realização de estágios pós-doutorais, geralmente financiados pelos órgãos de fomento à pesquisa do país ${ }^{7}$. A lamentar, nesse formato institucional, por falta de espaço e função, o desaparecimento do mestre - isto é, do criador de outros mestres, o incentivador dos novos pesquisadores, dos inventores, dos inovadores. Evidentemente, estamos falando aqui também do formador de outros professores, com características semelhantes às de seu mestre, constatada a desvalorização da função ensino no binômio dicotômico ensino/pesquisa. Enfim, desaparece o formador daqueles recursos humanos que um país de economia periférica realmente necessita para superar o grande desafio do desenvolvimento: o da reprodução não apenas do produtor de novos produtos (tecnológicos ou outros), mas de formas de pensar inovadoras, de criadores que modifiquem a linguagem da pesquisa e sua forma de criar produtos (tecnológicos, intelectuais), no sentido de vencer o fosso socioeconômico que nos separa do centro do dinamismo capitalista.

Um fato importante merece ser mencionado aqui, juntamente com a desvalorização social do professor, pela redução das atividades-fim da universidade à prática da pesquisa: é o não-reconhecimento institucional de que, se por um lado há os doutores sem vocação nem disposição para o ensino, 
há também aqueles que têm uma vocação explícita limitada à transmissão do conhecimento e, através dessa transmissão, à formação de novos mestres e pesquisadores. Mais uma vez, o professor Mezan nos esclarece e auxilia com sua reflexão:

"Sem querer desqualificar a função de pesquisador, deveríamos reconhecer que muitos professores, titulados ou não, não possuem vocação para produzir conhecimento novo, que é o que significa no sentido acadêmico a palavra 'pesquisa'. Seu talento é transmitir conhecimento já existente, algo tão necessário quanto pesquisar, especialmente nos cursos de graduação, nos quais se trata de equipar o aluno com o saber já acumulado naquela área de estudo" (MEZAN, 2005, p. 3).

$\mathrm{Na}$ verdade, atualmente é impensável que um professor se dedique especialmente ao ensino (nem falar em unicamente!), sobretudo o canônico, isto é, ao saber acumulado na área. Na pós-graduação estrito senso, embora se fale ainda no binômio ensino/pesquisa, a atividade-fim dos programas está completamente voltada para a pesquisa, o que constitui, do nosso ponto de vista, uma das razões explicativas do especialismo dos doutores em linhas de pesquisa. A formação de doutores tornou-se, nos últimos anos, uma verdadeira obsessão das políticas de educação e ciência e tecnologia ${ }^{8}$. Do nosso ponto de vista, ela é a radicalização do "pesquisismo" como estratégia pedagógica de superação da dependência tecnológica que mencionamos páginas atrás, a qual exprimiria e explicaria, segundo essa lógica, nossa situação atual de "atraso" face ao avanço econômico do núcleo central da economia capitalista.

Mais uma vez ratificamos nosso ponto de partida reflexivo: esta é uma opção trágica em termos de política educacional, pois quanto mais se concentra a prática da investigação no cume educacional, quanto mais valorizamos, elitizando, a atividade da pesquisa, em detrimento da qualidade do ensino superior como atividade-fim de formação de recursos humanos, menos capacidade teremos de criar uma sociedade sustentável em termos de produção, de consumo, de políticas públicas e de convivência social. Pois a base educacional do país, do ensino fundamental à graduação universitária, vai-se desvanecendo, perdendo conteúdo de integração e inserção social e econômica.

Já nossa escola fundamental, em centros urbanos como o Rio de Janeiro, começa a se submeter à ordem do crime organizado. O tráfico de drogas ou as igrejas pentecostalistas integram mais que a escola nas comunidades urbanas 
mais carentes. Forçoso é reconhecer que nossa atividade de pesquisa, sobretudo na pós-graduação, tem ainda pouco a ver com essa dura realidade. É mesmo esse destino social que almejamos como educadores?

Neste sentido, é muito importante reconhecer que a própria comunidade universitária está dividida quanto à dicotomia ensino/pesquisa (nem mencionemos aqui a terceira atividade-fim da universidade, dita "extensão", do nosso ponto de vista fruto do distanciamento das duas primeiras da realidade social). Os professores doutores, em processo de grande crescimento no ensino universitário desde os anos 90, sem sombra de dúvida tendem a considerar a atividade da pesquisa prioritária face ao ensino, sobretudo o ensino na graduação. Qualquer tentativa de reconhecer a atividade-fim ensino como prioritária na formação de recursos humanos é vista como tentativa de subestimar a atividade-fim pesquisa, e de transformar a universidade em "escolas de terceiro grau", tendência constatável nas universidades ou grupos universitários privados. Como os doutores, por obrigação institucional, se ocupam prioritariamente da pesquisa, buscam o aperfeiçoamento dessa atividade e do ensino através dessa atividade.

É nessa comunidade que a produtividade, como exigência de qualificação do pesquisador - que tende, aliás, a se tornar progressivamente "dura" - encontra seus maiores adeptos. Os avaliadores dos comitês de assessoramento das agências de fomento são recrutados geralmente entre os doutores com mais de cinco anos de trabalho em pós-graduação e com produção bibliográfica crescente. Não são nem juniores nem seniores: estão em ascensão ou no auge da carreira. Costumam ser competitivos e, às vezes, "mais realistas que o rei", isto é, tendem a aplicar com rigor as exigências das agências.

Esses são os "pares" que avaliam em suas áreas de competência seus colegas, não raro seus competidores. É verdade que muitas vezes procuram ter a visão de sua área como um todo, para que a "média produtiva" da mesma seja respeitada, mantendo uma perspectiva abrangente da produtividade em seu campo. Mas é também certo que muitas injustiças contra pesquisadores/ docentes com méritos são cometidas pelo rigor excessivo dos seus pares. Por isso consideramos, voltando ao tema introdutório de nosso trabalho, que o abutre mitológico mencionado na primeira página é representado atualmente pela própria comunidade científica, que, ratificando o poder olímpico do Estado, devora continuamente o fígado dos pequenos Prometeus da pesquisa, sem se dar conta de sua atitude autofágica. 


\section{Referências}

BOHMENI, H.; BIRMAN, J. (Orgs). As assim chamadas ciências sociais. Rio de Janeiro: Relume-Dumará, 1991.

BOURDIEU, P. O poder simbólico. Rio de Janeiro: Bertrand Brasil, 1989. . Contrafogos: táticas para enfrentar a invasão neoliberal. Rio de Janeiro: Zahar, 1998.

FIORI, J.L. Globalização, hegemonia e império. In: TAVARES, M. C.; FIORI, J. L. Poder e dinheiro: uma economia política da globalização. Petrópolis: Vozes, 1998. p. 87-147.

. Sistema mundial: império e pauperização para retomar o pensamento crítico latino-americano. In: FIORI, J. L.; MEDEIROS, C. Polarização mundial e crescimento. Petrópolis: Vozes, 2001. p. 39-75.

ÉSQUILO. Prometeu acorrentado. São Paulo: Martin Claret, 2004.

FURTADO, C. Cultura e desenvolvimento em época de crise. Rio de Janeiro: Paz e Terra, 1984.

Terra, 1974.

O mito do desenvolvimento econômico. Rio de Janeiro: Paz e

HARDT, M.; NEGRI, A. Império. São Paulo: Record, 2001.

KURZ, R. Os últimos combatentes. Petrópolis: Vozes, 1997.

LUZ, M. T. Cultura contemporânea e medicinas alternativas: novos paradigmas em saúde no fim do século XX. Physis, v. 7, n. 1, p. 13-43, 1997.As instituições médicas no Brasil: instituição e estratégia de hegemonia. Rio de Janeiro: Graal, 1979.

. Duas questões permanentes em um século de políticas de saúde no Brasil. Ciência \& Saúde Coletiva, Rio de Janeiro,v. 5, n. 2, p. 293-312, 2000 .

. Fragilidade social e busca de cuidado na sociedade civil de hoje. In: PINHEIRO, R.; MATTOS, R. A. (Orgs.). Cuidado: as fronteiras da integralidade. São Paulo: Hucitec, 2004a. p. 9-20.

O futuro do ensino das ciências sociais: por uma ética pedagógica. In: BOHMENI, H.; BIRMAN, J. (Orgs). As assim chamadas ciências sociais. 
Rio de Janeiro: Relume Dumará, 1991.

As instituições médicas no Brasil: instituição e estratégia de hegemonia. Rio de Janeiro: Graal, 1979.

. Medicina e ordem política brasileira. Rio de Janeiro: Graal, 1982.

. Natural, racional, social: razão médica e racionalidade científica moderna.São Paulo: Hucitec, 2004.

. Novos saberes e práticas em saúde coletiva: estudo sobre racionalidades Médicas e atividades corporais. São Paulo: Hucitec, 2003. p. 17-37.

. Políticas de descentralização e cidadania: novas práticas de saúde no Brasil atual. In: PINHEIRO, R.; MATTOS, R. A. Os sentidos da integralidade na atenção e no cuidado à saúde (Orgs.). Rio de Janeiro: IMS/UERJ, 2001. p. 17-37.

MEZAN, R. O escândalo dos doutores. Folha de São Paulo, São Paulo, 20 mar.2005, Caderno MAIS!, p.3.

SKIDMORE, T. Brasil de Getúlio a Castello. Rio de Janeiro: Paz e Terra, 1975.

TAVARES, M.C.; SERRA, J.: "Além da estagnação: uma discussão sobre o estilo de desenvolvimento recente no Brasil”, In: SERRA, J. América Latina: ensaios de interpretação econômica. Rio de Janeiro, Paz e Terra, 1976.

\section{NOTAS}

* Socióloga; professora titular do Departamento de Políticas e Instituições de Saúde do IMS/ UERJ; vice-presidente da Associação Brasileira de Saúde Coletiva (ABRASCO); coordenadora do grupo de pesquisa Racionalidades Médicas do CNPq, em desenvolvimento no IMS/UERJ; pesquisadora associada do Laboratório de Pesquisas sobre Práticas de Integralidade em Saúde (LAPPIS).Endereço eletrônico: madelluz@superig.com.br.

${ }^{1}$ Esta é uma questão crucial, a nosso ver, que nunca é levada em consideração pelos órgãos de fomento à pesquisa: a qualidade do produto mesmo, isto é, sua real contribuição ao avanço do conhecimento ou a inovação tecnológica de que é capaz . Geralmente o argumento que ouvimos nas comissões de avaliação de produtividade de pesquisadores e programas é singela: "é 
impossível avaliar produtos" (porque seriam milhares, e quem garantiria sua qualidade?). É preciso começar a pensar seriamente em criar instrumentos de avaliação dos produtos resultantes das atividades de investigação...

${ }^{2}$ Celso Furtado defendeu, desde suas primeiras obras na década de 50, a idéia de que o desenvolvimento econômico de um país não pode ser pensado independente de um projeto de desenvolvimento social, no qual se sobressai, como política estratégica prioritária, a educação. Para esse economista, não existiria possibilidade de superação do estágio de "subdesenvolvimento" e "dependência" das nações latinoamericanas sem uma transformação estrutural que implicasse acessibilidade universal da educação como forma de sustentação do crescimento econômico, e do avanço tecnológico necessários para aceder a uma economia capitalista madura. A noção de desenvolvimento se diferencia, nesse pensamento, claramente da de crescimento econômico, embora não haja separação entre as duas. Entre os brazilianistas, Thomas Skidmore, talvez o pioneiro deles, reafirma a necessidade desse projeto em declarações recentes à Folha de São Paulo (20/03/05, Caderno MAIS!, p. 3), acentuando a urgente necessidade de voltar-se ao paradigma desenvolvimentista, centrado na educação.

${ }^{3}$ Para que não haja suspeita de alguma ideologia nacional desenvolvimentista nestas afirmações, mas uma constatação factual de possível fracasso da concepção de desenvolvimento associado ao crescimento da produção tecnológica, podemos ler no caderno econômico da Folha de São Paulo, de 9 de abril deste ano, afirmações de economistas, executivos e líderes de pesquisa de órgãos como o IPEA, que demonstram que continuamos exportadores de tecnologia média e baixa e importadores de tecnologia elevada ("a que conta" em termos de equilíbrio de balança e de passagem de fase econômica): "O Brasil perdeu o rumo (do desenvolvimento da indústria eletrônica). Hoje você tem uma indústria de tecnologia que basicamente é de montagem, afirma Ivair Rodrigues, gerente de pesquisas da IDC, consultoria especializada em tecnologia da informação". E mais adiante: "Para alguns economistas, como Augusto Lopez-Claros, diretor executivo do Fórum Econômico Mundial, o processo de montagem de componentes pode ser só uma etapa: "muitos países, A Coréia por ex., já passaram por esta fase”. Mas para que essa seja apenas uma fase transitória, alertou, serão precisos investimentos urgentes em educação no Brasil” (Folha de São Paulo, 09/04/2005, p. B-1, artigo de Maeli Prado e Cíntia Cardoso).

${ }^{4}$ Sabemos do papel da pesquisa científica na transformação da vida natural, do meio ambiente e da própria vida social desde o início da modernidade (LUZ, 2004b). Essa colocação está feita desde as primeiras páginas do artigo, e como pesquisadora, não nos interessa diminuir esse papel. Trata-se aqui de analisar as condições sociais e institucionais em que se está dando a produção da pesquisa científica e seus danos para a saúde. 
${ }^{5}$ Evidentemente, há variações no quadro impressionista aqui esboçado. Um exemplo: por necessidades acadêmicas de caráter pessoal e institucional (formar doutores para o programa), desenvolvemos nosso doutorado em Ciências Sociais na USP no tempo recorde para a época, de 51 meses, entre 1974 e 1978, mas de acordo com diferentes áreas disciplinares, esse podia ser um prazo médio. Por outro lado, sabia-se de casos - não raros - de professores da área de Ciências Humanas que arrastavam há cerca de uma década seus estudos doutorais, sem conseguir defender suas teses, fato que podia acontecer também no mestrado.

${ }^{6}$ Temos tido a oportunidade de participar de bancas de concursos para professores doutores como porta de entrada no ensino universitário já em nível de adjunto (caso das universidades federais): é de lamentar a mediocridade das aulas dadas por alguns desses candidatos, aprovados graças ao seu Currículo Lattes e à entrevista, que escondem sua incapacidade pedagógica...

${ }^{7}$ É impressionante o processo em marcha de pós-doutorização das pós-graduações. Já não basta mais ser um "simples" doutor, é necessário, para benefício de seu currículo, que o docente/ pesquisador realize "cursos" de pós-doutorado que começam a ser vistos como titulação, e não mais como estágios, tornando-se diferencial em concursos públicos para a carreira docente.

${ }^{8}$ A julgar pela reportagem de 10/04/2005 de O Globo, intitulada "Apenas 38\% das universidades do país têm doutorado", (p.12, O País), pela reforma universitária cujo projeto está em discussão, a existência de cursos de formação de doutores tornar-se-á condição de sobrevivência para universidades ou grupos universitários privados. A suposição da política governamental é que cursos de mestrado e doutorado demonstram que a universidade ou o complexo universitário privado está comprometido com a pesquisa, pois formará doutores, em curto ou médio prazos. Essa é uma suposição temerária, além de ingênua, considerando-se as estratégias que as universidades ou grupos privados de ensino universitário podem desenvolver (algumas já desenvolvem para simples credenciamento de mestrados) para "provar" que estão desenvolvendo pesquisa. 
Prometheus Bound: a Sociological Analysis of the Category Productivity and Current Conditions in Academic Life

This article proposes to analyze relations in contemporary society between intellectual output and the category "productivity", viewed as a privileged manifestation of scientific knowledge. The category has been imported from economics and applied to intellectual work. The aim is to show how the logic of machine-like productivity or that of specific sectors in knowledge output, without harming researchers' health or even scientific productivity itself, overlook the objectives, rhythms, and forms of producing and disseminating the multiple disciplinary versions of scientific work.

Key words: Science; research; productivity; work; distress. 